\title{
Numerical simulation of heat and mass transport during hydration of Portland cement mortar in semi-adiabatic and steam curing conditions
}

\author{
E.Hernandez-Bautista ${ }^{1,2^{*}}$, D. P. Bentz ${ }^{2}$, S. Sandoval-Torres ${ }^{1}$, P. F. de J. Cano-Barrita ${ }^{1}$ \\ ${ }^{1}$. Instituto Politécnico Nacional/CIIDIR Unidad Oaxaca, Hornos 1003, Oaxaca, México. 71230. \\ ${ }^{2}$. National Institute of Standards and Technology, Gaithersburg, MD, USA. \\ *Corresponding author: ehernandezb0800@alumno.ipn.mx
}

\begin{abstract}
A model that describes hydration and heat-mass transport in Portland cement mortar during steam curing was developed. The hydration reactions are described by a maturity function that uses the equivalent age concept, coupled to a heat and mass balance. The thermal conductivity and specific heat of mortar with water-to-cement mass ratio of 0.30 was measured during hydration, using the Transient Plane Source method. The parameters for the maturity equation and the activation energy were obtained by isothermal calorimetry at $23{ }^{\circ} \mathrm{C}$ and $38^{\circ} \mathrm{C}$. Steam curing and semi-adiabatic experiments were carried out to obtain the temperature evolution and moisture profiles were assessed by magnetic resonance imaging. Three specimen geometries were simulated and the results were compared with experimental data. Comparisons of temperature had maximum residuals of $2.5^{\circ} \mathrm{C}$ and $5{ }^{\circ} \mathrm{C}$ for semi-adiabatic and steam curing conditions, respectively. The model correctly predicts the evaporable water distribution obtained by magnetic resonance imaging.
\end{abstract}

Keywords: Accelerated curing; cement-based materials; moisture distribution; exothermic reaction; isothermal calorimetry; nuclear magnetic resonance

\section{Nomenclature}

$a$ Parameter for vapor diffusion coefficient $\mathrm{kg} /(\mathrm{m} \cdot \mathrm{s})$

$b$ Parameter for the liquid diffusion coefficient

$c$ Parameter for the liquid diffusion coefficient

$C_{p}{ }^{\text {CemBM }}$ Cement-based material specific heat capacity $\mathrm{J} /(\mathrm{kg} \cdot \mathrm{K})$

$C_{p i}$ Specific heat capacity of the material i $\mathrm{J} /(\mathrm{kg} \cdot \mathrm{K})$

$D_{l}$ Liquid moisture diffusion coefficient $\mathrm{m}^{2} / \mathrm{s}$

$D_{v}$ Vapor diffusion coefficient $\mathrm{kg} /(\mathrm{m} \cdot \mathrm{s})$

$\boldsymbol{E}$ Activation energy $\mathrm{J} / \mathrm{mol}$

$H$ Total enthalpy of hydration $\mathrm{J} / \mathrm{kg}$

$H_{u}$ Ultimate enthalpy of hydration $\mathrm{J} / \mathrm{kg}$

$h_{c}$ Convective heat transfer coefficient $\mathrm{W} /\left(\mathrm{m}^{2} \cdot \mathrm{K}\right)$

$h_{m}$ Mass transfer coefficient $\mathrm{g} /\left(\mathrm{m}^{2} \cdot \mathrm{h} \cdot \mathrm{Pa}\right)$ or $\mathrm{s} / \mathrm{m}$

$i$ type of Material

$k_{l}$ Hashin-Shtrikman lower bound for the thermal conductivity $\mathrm{W} /(\mathrm{m} \cdot \mathrm{K})$

$k_{h}$ Hashin-Shtrikman upper bound for the thermal conductivity $\mathrm{W} /(\mathrm{m} \cdot \mathrm{K})$

$k_{1}$ Thermal conductivity of cement powder $\mathrm{W} /(\mathrm{m} \cdot \mathrm{K})$

$k_{2}$ Thermal conductivity of silica sand $\mathrm{W} /(\mathrm{m} \cdot \mathrm{K})$

$k_{i}$ Thermal conductivity of material i $\mathrm{W} /(\mathrm{m} \cdot \mathrm{K})$

$M_{f}{ }^{\text {water }}$ Water mass fraction

$M_{f}{ }^{\text {Bondwater }}$ Bound water mass fraction

$M_{f}{ }^{\text {cem }}$ Cement mass fraction 
$M_{f}$ silicasand Aggregate mass fraction

$\overrightarrow{\mathbf{n}}$ Normal vector

$P_{\text {vext }}$ Vapor pressure in the surroundings $\mathrm{Pa}$

$P_{v}$ Vapor pressure inside the material $\mathrm{Pa}$

$\boldsymbol{Q}$ Heat generation rate $\mathrm{W} / \mathrm{m}^{3}$

$R$ Ideal gas constant $\mathrm{J} /(\mathrm{mol} \cdot \mathrm{K})$

$S$ Evaporable water sink $\mathrm{kg} /\left(\mathrm{m}^{3} \cdot \mathrm{s}\right)$

$\mathrm{S}_{\mathrm{p}}$ Surface of the pore system $\mathrm{m}^{2}$

$t$ Time $\mathrm{s}$

$T_{r}$ Reference temperature $\mathrm{K}$

$T$ Temperature $\mathrm{K}$

$t_{e}$ Equivalent time

$T_{2}$ transverse relaxation time (s)

$x_{1}$ Volume fraction of cement powder in the mix

$x_{2}$ Volume fraction of silica sand in the mix

$V_{p}$ Volume of the pore system $\mathrm{m}^{3}$

$w$ Moisture content

Greek symbols

$\alpha$ Degree of hydration

$\alpha_{u}$ Ultimate degree of hydration

$\beta$ Maturity equation parameter

$\lambda_{\text {vap }}$ Heat of vaporization $\mathrm{J} / \mathrm{kg}$

$\rho_{i}$ Density of material i $\mathrm{kg} / \mathrm{m}^{3}$

$\rho_{s}$ Density of the solid cement-based material $\mathrm{kg} / \mathrm{m}^{3}$

$\rho_{2}$ Surface relaxivity $\mathrm{m} / \mathrm{s}$

$\tau$ Maturity equation parameter $\mathrm{s}$

$\Omega$ Domain

\section{Introduction}

Steam curing of hydraulic concrete in the precast industry has the advantage of accelerating the hydration reactions of cement. Consequently, the material develops compressive strength and reduces its permeability in hours, compared to standard curing under normal environmental conditions, where the hydration reactions may require several days or even months to reach an adequate level [1].

The process of steam curing consists of increasing the temperature within a saturated water vapor atmosphere. In this process, the cement hydration has a significant impact on the temperature development inside the material at early ages [2] and also affects the mechanical and durability properties of the hardened material. Therefore, it is essential to take into account the hydration properties and temperature development to prevent premature damage to concrete.

Studies related to steam curing of concrete have been oriented toward the development of compressive strength [3-6], pore structure development [7-9] and energetic efficiency of this process $[5,10]$.

In order to understand the mechanisms of heat and mass transport coupled with cement hydration, various models have been developed to explain these phenomena [11-17]. However, these are typically for ambient environmental conditions, therefore it is necessary to focus on hydration at elevated temperatures and high relative humidity encountered in steam curing. Additionally, the calculated degree of hydration varies with temperature during the curing cycle. This is of interest to 
the precast industry. With the aims of improving curing schedules, establishing appropriate curing conditions, improving mechanical properties and durability of cement-based materials and obtaining a better energy efficiency in the process, this paper investigates the numerical simulation of this curing process.

Specifically, the aim of this work is to model the hydration, moisture distribution and heat transport during the semi-adiabatic curing of cement paste and mortar specimens so that pre-cast operations can be optimized with respect to curing (cycle) time and energy efficiency. Nuclear magnetic resonance (NMR) and magnetic resonance imaging (MRI) measurements are performed to nondestructively obtain experimental evidence of the moisture distribution in small mortar specimens to validate the model predictions.

\section{Experimental procedures}

\subsection{Materials}

The cement used in the mortar specimens was a Mexican cement designated as CPO30RS. The oxide composition measured by X-ray fluorescence is shown in Table 1. The corresponding potential Bogue phase composition, heat of hydration and water necessary for cement hydration were calculated. The latter two sets of values were obtained by multiplying the Bogue mass fractions by the accepted value for each phase as taken from the literature.

The cement density and its particle size distribution (PSD) via laser diffraction were measured at the National Institute of Standards and Technology (NIST). A density of $3150 \mathrm{~kg} / \mathrm{m}^{3} \pm 10 \mathrm{~kg} / \mathrm{m}^{3}$ was obtained using the ASTM C188 test method [18] and the measured PSD is given in Figure 1. The mortar mixture proportions used in this study are provided in Table 2. Silica sand with a fineness modulus of 2.9 was used as fine aggregate. The cement, water and silica sand were mixed according to the ASTM C305-06 standard [19].

Table 1. Oxides and potential Bogue phase composition of Mexican cement CPO30RS

\begin{tabular}{lllc}
\hline Oxide & \% Mass & \multicolumn{3}{l}{ Phase \% mass } & 0.553 \\
$\mathrm{CaO}$ & 62.5 & $\mathrm{C}_{3} \mathrm{~S}$ & 0.200 \\
$\mathrm{SiO}_{2}$ & 21.5 & $\mathrm{C}_{2} \mathrm{~S}$ & 0.089 \\
$\mathrm{Al}_{2} \mathrm{O}_{3}$ & 4.5 & $\mathrm{C}_{3} \mathrm{~A}$ & 0.055 \\
$\mathrm{MgO}$ & 2.5 & $\mathrm{C}_{4} \mathrm{AF}$ & 286. \\
\cline { 3 - 4 } $\mathrm{TiO}_{2}$ & 2.0 & Heat of hydration, $\mathrm{H}_{\mathrm{u}}(\mathrm{J} / \mathrm{g}$ cement) & {$[20]$} \\
\cline { 3 - 4 } $\mathrm{Fe}_{2} \mathrm{O}_{3}$ & 1.8 & $\mathrm{C}_{3} \mathrm{~S}$ contribution & 52.4 \\
$\mathrm{Mn}_{2} \mathrm{O}_{3}$ & 1.5 & $\mathrm{C}_{2} \mathrm{~S}$ contribution & 101.6 \\
$\mathrm{~K}_{2} \mathrm{O}$ & 1.5 & $\mathrm{C}_{3} \mathrm{~A}$ contribution & 39.7 \\
$\mathrm{SO}_{3}$ & 1.0 & $\mathrm{C}_{4} \mathrm{AF}$ contribution & 0.133 \\
\cline { 3 - 4 } $\mathrm{Na}_{2} \mathrm{O}$ & 0.7 & Water necessary for hydration $(\mathrm{g} / \mathrm{g}$ cement) $[21]$ \\
\cline { 3 - 4 } $\mathrm{P}_{2} \mathrm{O} 5$ & 0.5 & $\mathrm{C}_{3} \mathrm{~S}$ contribution & 0.042 \\
$\mathrm{Total}$ & 100 & $\mathrm{C}_{2} \mathrm{~S}$ contribution & 0.036 \\
& & $\mathrm{C}_{3} \mathrm{~A}$ contribution & 0.020 \\
Density & $3150 \mathrm{~kg} / \mathrm{m}^{3}$ & $\mathrm{C}_{4} \mathrm{AF}$ contribution & \\
& & &
\end{tabular}




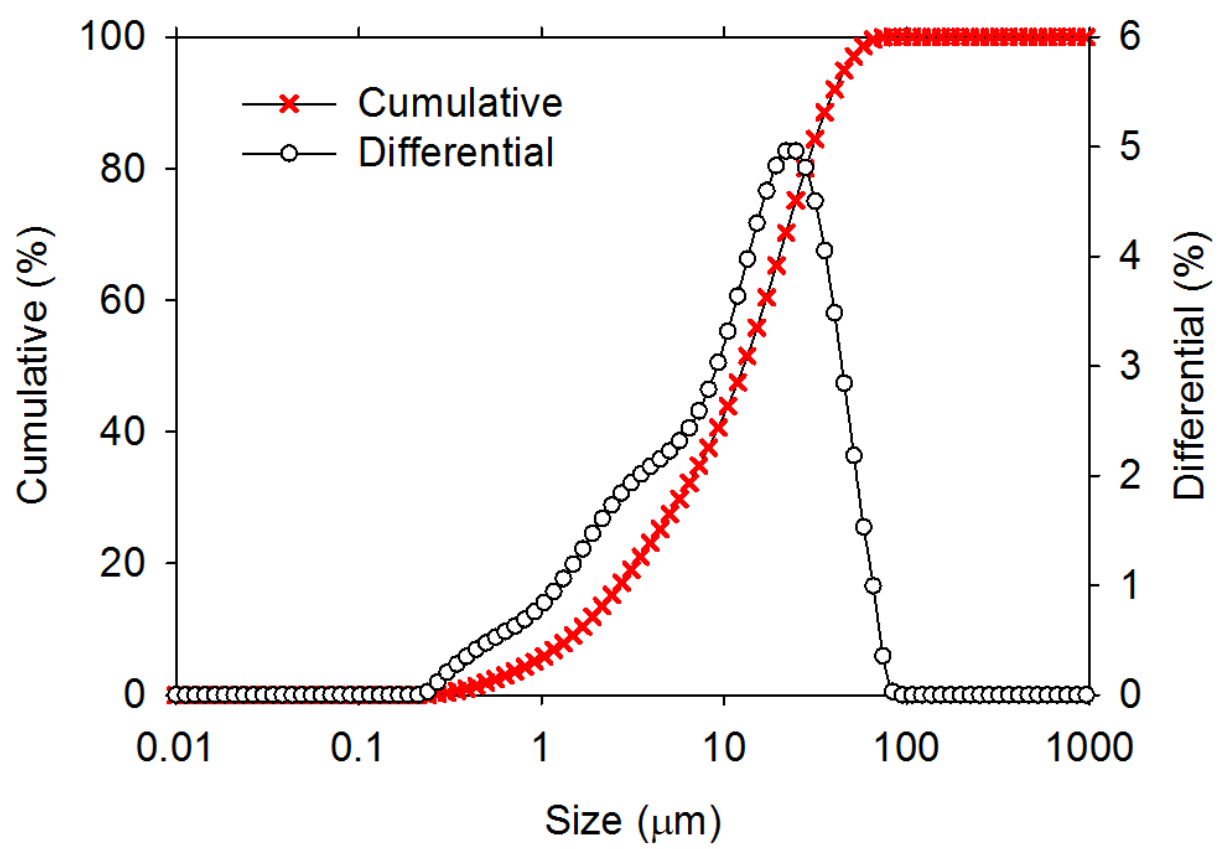

Figure 1. Cumulative and differential PSD of the cement CPO 30RS.

Table 2. Mortar mixture proportions $(w / c=0.30)$

\begin{tabular}{ccc}
\hline Material & Proportion, $\mathrm{kg} / \mathrm{m}^{3}$ & Mass fraction \\
\hline CPO30RS cement & 647.81 & 0.271 \\
Water & 194.34 & 0.081 \\
Silica sand (Dry) & 1548.00 & 0.648 \\
Computed Density & 2390.16 & \\
\hline
\end{tabular}

\subsection{Method}

\subsubsection{Thermal property changes during cement hydration}

\subsubsection{Heat capacity}

The Transient Plane Source (TPS) method uses a sensor that consists of a combined heat source and a resistance thermometer [22]. A constant power is supplied to the sensor for a specified period of time and the temperature is continuously measured. The thermal properties of the sample are calculated by analyzing the temperature development in the sensor.

For cement and dry silica sand, the heat capacity was measured using a Hot Disk Thermal Constant Analyzer with a heat capacity unit, consisting of a probe attached to the base of a gold pan/lid. For these measurements, the gold pan and its lid were insulated with polystyrene to prevent heat loss. First, a reference measurement with the empty pan was made, followed by measurements with the specimen placed in the pan. A power of $0.1 \mathrm{~W}$ was applied for a measurement time of $80 \mathrm{~s}$ [23]. For the quantitative analysis, the acquired data points in the range of 100 to 200 out of 200 total data points were used. Knowing the mass of the specimen, the heat capacity for each material was calculated in $\mathrm{J} /(\mathrm{kg} \cdot \mathrm{K})$. The average values are shown in Table 3, along with the standard deviations from replicate measurements. 
Table 3. Heat capacity of the materials

\begin{tabular}{ccc}
\hline Material & $\mathrm{C}_{\mathrm{p}}[\mathrm{J} /(\mathrm{kg} \cdot \mathrm{K})]$ & $\begin{array}{c}\text { Standard } \\
\text { deviation } \\
{[\mathbf{J} /(\mathbf{k g} \cdot \mathbf{K})]}\end{array}$ \\
\hline Cement powder & 722.5 & 6.1 \\
Silica sand & 635.3 & 2.8 \\
Water & 4180 & \\
Bound water & $2090[23]$ & \\
\hline
\end{tabular}

The heat capacity of the mortar during hydration was calculated using Equation 1 [23] (mass-based average), taking into account the initial mass fractions given in Table 2 and neglecting any mass loss during curing. It was assumed that the mass fraction of evaporable water decreases with increasing degree of hydration, while the chemically bound water mass fraction increases.

$$
C_{p}^{\text {CemBM }}=4180 M_{f}^{\text {water }}+2090 M_{f}^{\text {boundwater }}+722.5 M_{f}^{\text {cem }}+635.3 M_{f}^{\text {SilicaSand }}
$$

where $M_{f}^{\text {water }}=M_{f \text {,initial }}^{\text {water }}(1 \quad)$ is the time-varying mass fraction of evaporable water in the cement paste, $M_{f}^{\text {boundwater }}=M_{f \text {,initial }}^{\text {water }} \quad$ is the time-varying mass fraction of water chemically bound in the hydrated cement paste, $\mathbf{M}_{\mathrm{f}}^{\mathrm{cem}}$ is the initial mass fraction of cement in the mortar, and $\mathbf{M}_{\mathrm{f}}^{\text {silicasand }}$ is the mass fraction of silica sand in the mortar (Table 2).

\subsubsection{Thermal conductivity}

Thermal conductivity measurements were undertaken on mortar cubes measuring $50.8 \mathrm{~mm}$ on a side. The cubes were cured in sealed conditions inside two plastic bags and stored in an environmental chamber at $23{ }^{\circ} \mathrm{C} \pm 1{ }^{\circ} \mathrm{C}$. The measurements were performed at $1 \mathrm{~d}, 2 \mathrm{~d}, 3 \mathrm{~d}, 4 \mathrm{~d}$, and $8 \mathrm{~d}$ of age. Three pairs of cubes, placed in partially sealed plastic bags to avoid mass loss and evaporative cooling during the testing, were evaluated using the TPS method. A Ni foil encased in a Kapton probe was used as the sensor. The probe was horizontally sandwiched between the cast sides of the two hardened specimens. After an equilibration time of at least $45 \mathrm{~min}$ in the laboratory, nominally maintained at $23{ }^{\circ} \mathrm{C}$, measurements were performed with a power of $0.30 \mathrm{~W}$ for a measurement time of $10 \mathrm{~s}$. The measured response of the probe sensor was analyzed using the builtin software to determine the thermal conductivity and volumetric heat capacity of the specimens. The analyzer samples 200 points during $10 \mathrm{~s}$, but only the points in the range 100 to 200 were used in the quantitative analysis. Three different pairs of mortar cubes were analyzed in this manner and the average value and standard deviation were computed.

Figure 2 shows the values of thermal conductivity and specific heat obtained. A small variation of the thermal properties with hydration time is observed. The experimental values (red points) of specific heat were obtained as well as the thermal conductivity (blue triangles). Because the TPS method provided the value of thermal diffusivity, based on this data, the value of the volumetric specific heat was transformed into specific heat in units of $\mathrm{J} /(\mathrm{kg} \cdot \mathrm{K})$. The densities of the material were calculated from the actual dimensions and masses of the specimens. 


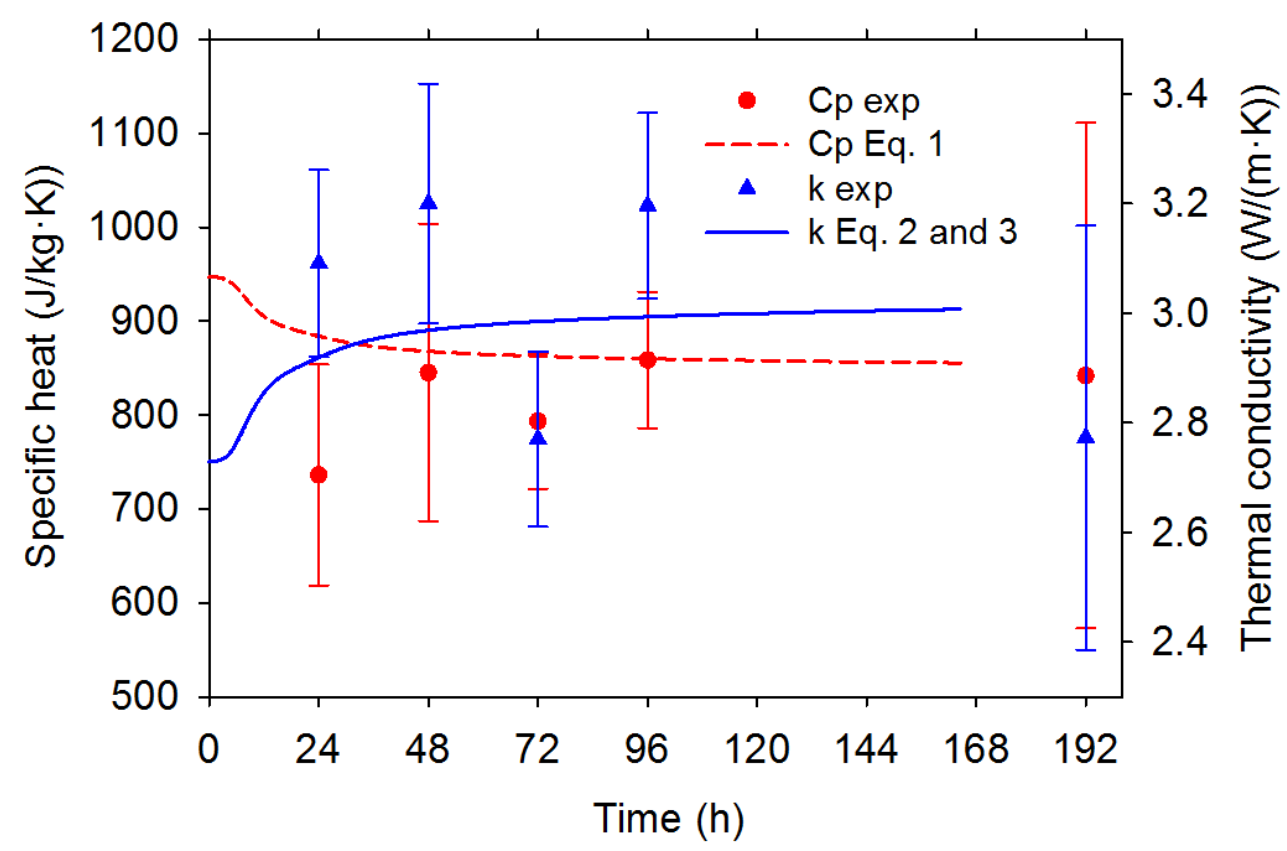

Figure 2. Thermal conductivity and specific heat capacity of mortar with $w / c=0.30$. The error bars represent one standard deviation.

The thermal conductivity of the mortar was also calculated using the bounds of Hashin-Shtrikman [23], shown in Figure 2 as the solid blue line, as the average of the lower $\left(k_{l}\right)$ and upper $\left(k_{u}\right)$ bounds for thermal conductivity of a two-phase material. Equations (2) and (3) were used to calculate the thermal conductivity as a function of the volume fraction of the hydrated cement paste $\left(x_{1}\right)$ and the silica sand $\left(x_{2}\right)$. The obtained value was $2.8 \mathrm{~W} /(\mathrm{m} \cdot \mathrm{K})$ for the mortar with a $w / c$ ratio of 0.30 . The bounds are given by:

$$
\begin{aligned}
& k_{l}=k_{1}+\frac{x_{2}}{\frac{1}{k_{2} k_{1}}+\frac{x_{1}}{3 k_{1}}} \\
& k_{h}=k_{2}+\frac{x_{1}}{\frac{1}{k_{1} k_{2}}+\frac{x_{2}}{3 k_{2}}}
\end{aligned}
$$

where $k_{l}$ was taken as $1 \mathrm{~W} /(\mathrm{m} \cdot \mathrm{K})$ for the cement paste [23] and $k_{2}$ was calculated as $5 \mathrm{~W} /(\mathrm{m} \cdot \mathrm{K})$ for the silica sand, according to the procedure described next. The value of 5 is on the lower end of the range of $5 \mathrm{~W} /(\mathrm{m} \cdot \mathrm{K})$ to $8 \mathrm{~W} /(\mathrm{m} \cdot \mathrm{K})$ found in the literature for siliceous aggregates [23].

Based on the volumetric proportions of slurries prepared with only water and silica sand, the thermal conductivity of the mix was measured using the aforementioned TPS method. Knowing the thermal conductivity of water, equations (2) and (3) were then used to estimate the thermal conductivity of silica sand. 


\subsubsection{Isothermal calorimetry}

Using the mortar mixture proportions shown in Table 2, the heat release and heat flow during cement hydration were measured using a TAM air isothermal calorimeter ${ }^{1}$ [24]. A sample of about $4 \mathrm{~g}$ to $8 \mathrm{~g}$ of each prepared mixture was placed into a $20 \mathrm{~mL}$ glass ampoule and sealed. The measurements were made according to the user's manual procedure, during $7 \mathrm{~d}$ to $9 \mathrm{~d}$ at $23{ }^{\circ} \mathrm{C}$ and $38^{\circ} \mathrm{C}$. The samples were cured under sealed conditions in the calorimeter.

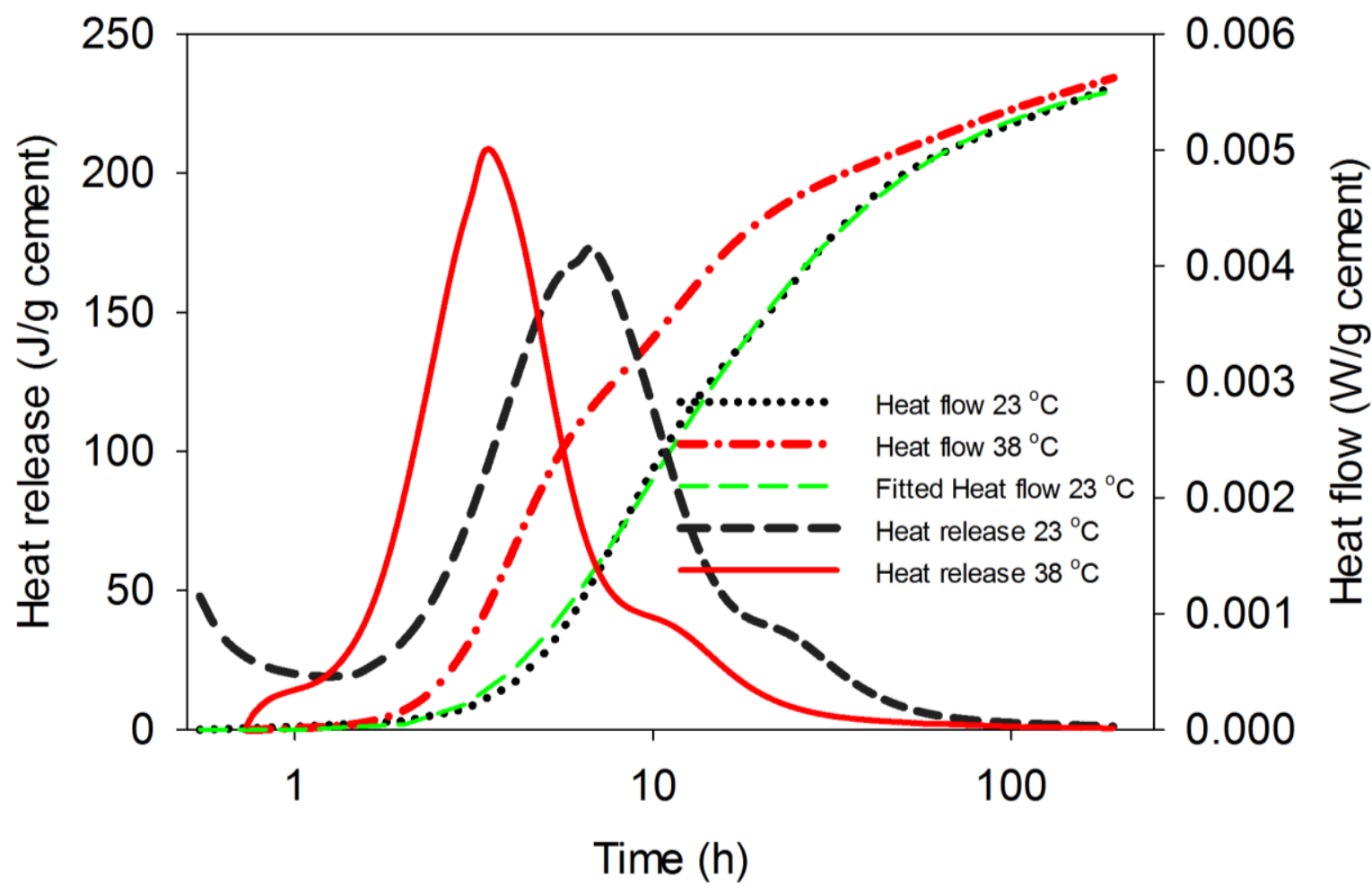

Figure 3. Heat flow and heat release curves of mortar $w / c=0.30$.

Based on the information shown in Figure 3, the parameters of the maturity model (Table 4) were obtained by fitting the curve of cumulative heat release at $23^{\circ} \mathrm{C}$ to the maturity equation (Equation $4)$, in order to obtain the parameters $\alpha_{\mathrm{u}}, \beta$, and $\tau$. The activation energy $(\mathrm{J} / \mathrm{mol})$ was obtained from Equation (5), where the concept of equivalent time (equivalent age) was used to compare the two data sets at $23^{\circ} \mathrm{C}$ and $38^{\circ} \mathrm{C}$ [25] The isothermal calorimetry tests were performed on cement pastes at $23{ }^{\circ} \mathrm{C}, 38{ }^{\circ} \mathrm{C}$, and $60{ }^{\circ} \mathrm{C}$. For the mortars, they were performed at $23{ }^{\circ} \mathrm{C}$ and $38{ }^{\circ} \mathrm{C}$ (Table 4), providing similar values compared to the cement pastes at the same temperatures. Therefore, the value at $60{ }^{\circ} \mathrm{C}$ obtained for the cement paste was also taken for the mortar.

$$
\frac{d}{d t}=\exp \frac{E}{R} \frac{1}{T_{r}} \frac{1}{T} \div \frac{u}{t_{e}} \frac{-}{t_{e}} \div \exp \quad \frac{-}{t_{e}} \div, t=0 \text { then }=0
$$

where $\alpha\left(t_{e}\right)$ is the degree of hydration at equivalent age $t_{e}, \tau$ is the hydration time (h), $\beta$ is the hydration shape parameter, which represents the slope of the linear portion of the hydration-time relationship (larger values of $\beta$ indicate a faster hydration rate), $\alpha_{u}$ is the final degree of hydration [2]. Values of these parameters for the mortar with $w / c=0.30$ are given in Table 4.

\footnotetext{
${ }^{1}$ Certain commercial products are identified in this paper to specify the materials used and procedures employed. In no case does such identification imply endorsement or recommendation by the National Institute of Standards and Technology, nor does it indicate that the products are necessarily the best available for the purpose.
} 


$$
\frac{d t_{e}}{d t}=\exp \frac{E}{R} \frac{1}{T_{r}} \quad \frac{1}{T} \div, t=0 \text { then } t_{e}=0
$$

where $t_{e}$ is the equivalent time or equivalent age at the reference curing temperature, $d t$ is the differential time (interval) $(\mathrm{h}), T$ is the average concrete temperature during the interval $d t(\mathrm{~K}), T_{r}$ is the constant reference temperature (taken to be $296.15 \mathrm{~K}$ in this study), $\boldsymbol{E}$ is the activation energy $(\mathrm{J} / \mathrm{mol})$ and $\boldsymbol{R}$ is the universal gas constant $(8.314 \mathrm{~J} /(\mathrm{mol} \cdot \mathrm{K}))$. According to Jonasson et al. [26], there is an almost linear relationship between the temperature and the activation energy in the range of $23{ }^{\circ} \mathrm{C}$ and higher. In our model, this relationship was considered by interpolating the values given in Table 4.

Table 4 Maturity parameters and activation energy for the mortar obtained by fitting the isothermal calorimetry data to Equation 4 (Correlation coefficient $=0.998$ )

\begin{tabular}{ccc}
\hline Maturity parameters & Value & $\begin{array}{c}\text { Standard } \\
\text { error }\end{array}$ \\
\hline$\alpha_{\mathrm{u}}$ & 0.50 & 0.001 \\
$\tau$ & 10.09 & 0.132 \\
$\beta$ & 0.98 & 0.016 \\
Activation energy E 23 & $32800(\mathrm{~J} / \mathrm{mol})$ & \\
Activation energy E 60 & $25800(\mathrm{~J} / \mathrm{mol})$ & \\
\hline
\end{tabular}

\subsubsection{Semi-adiabatic calorimetry experiments (Type A specimens)}

A semi-adiabatic calorimetry experiment was undertaken during $7 \mathrm{~d}$ to measure the temperature evolution during hydration of the mortar. About $300 \mathrm{~g}$ of mortar was used to cast a Type A cylinder in a low-density polyethylene (LDPE) container $(\phi 46 \mathrm{~mm}$ x $99 \mathrm{~mm})$. The calorimeter has a semiadiabatic configuration and contains a micro-silica insulation $(\mathrm{k}=0.036 \mathrm{~W} /(\mathrm{m} \cdot \mathrm{K})$ and thickness $=0.065 \mathrm{~m}$ ) wall and a single thermocouple inserted approximately midway into the specimen to record the temperature. The maximum heat loss was $8 \mathrm{~J} / \mathrm{h} / \mathrm{K}$, which is less than the $100 \mathrm{~J} / \mathrm{h} / \mathrm{K}$ required by RILEM [27] for a calorimeter to be considered as semi-adiabatic.

\subsubsection{Steam curing experiments}

\subsubsection{Type B specimens under steam curing}

Type B cylindrical mortar specimens $(\phi 100 \mathrm{~mm} \times 200 \mathrm{~mm})$ were cast in polystyrene insulated polyvinyl chloride (PVC) molds. The PVC prevents the mass transport in the radial direction. Only one face of the specimens was not insulated, so that heat and mass transport are unidirectional through this face. Before pouring the mortar into the molds, type $\mathrm{K}$ thermocouples with a range of $-130{ }^{\circ} \mathrm{C}$ to $90{ }^{\circ} \mathrm{C}$ and an accuracy of $\pm 0.28{ }^{\circ} \mathrm{C}$ were placed to monitor the temperature changes during curing/hydration at seven evenly spaced locations along the specimens. The initial temperature of the mortar was $24^{\circ} \mathrm{C}$. The experimental setup within the environmental chamber is shown in Figure 4. The temperature and relative humidity inside the chamber were recorded with a thermo-hygrometer having a range of $0 \%$ to $100 \%$ and an accuracy of $\pm 2.5 \%$. 


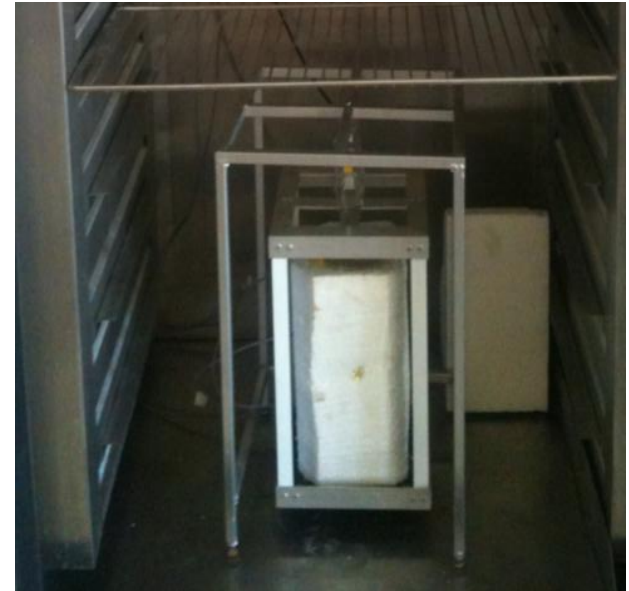

a)

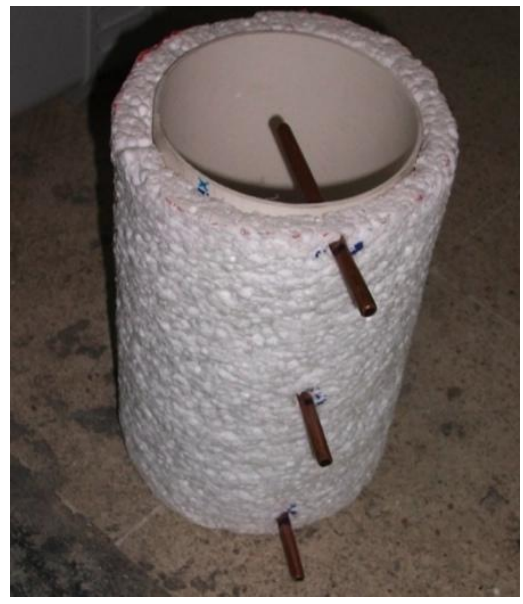

b)

Figure 4. a) Experimental setup inside the environmental chamber, and b) Polystyrene insulated PVC mold for Type B specimens, showing only three of the seven holes for the thermocouples.

Once the specimens were cast, they were kept inside the environmental chamber at approximately $100 \%$ relative humidity and $24{ }^{\circ} \mathrm{C}$ for a period of $3 \mathrm{~h}$. Temperature readings at seven locations were taken every minute throughout the entire curing process of $18 \mathrm{~h}$, starting immediately after casting. This provided the spatial temperature distribution inside the specimens. The locations of thermocouples were labeled from 1 to 7 ( 1 being the thermocouple on the concrete surface and 7 the thermocouple at the insulated base of the cylinder). Then, the specimens were subjected to the steam-curing schedule shown in Figure 5, which is based on the ACI 517-2R-80 Standard for an accelerated curing with water vapor at atmospheric pressure [28]. Addition of a steam generator was necessary in order to ensure the required temperature and relative humidity within the environmental chamber.

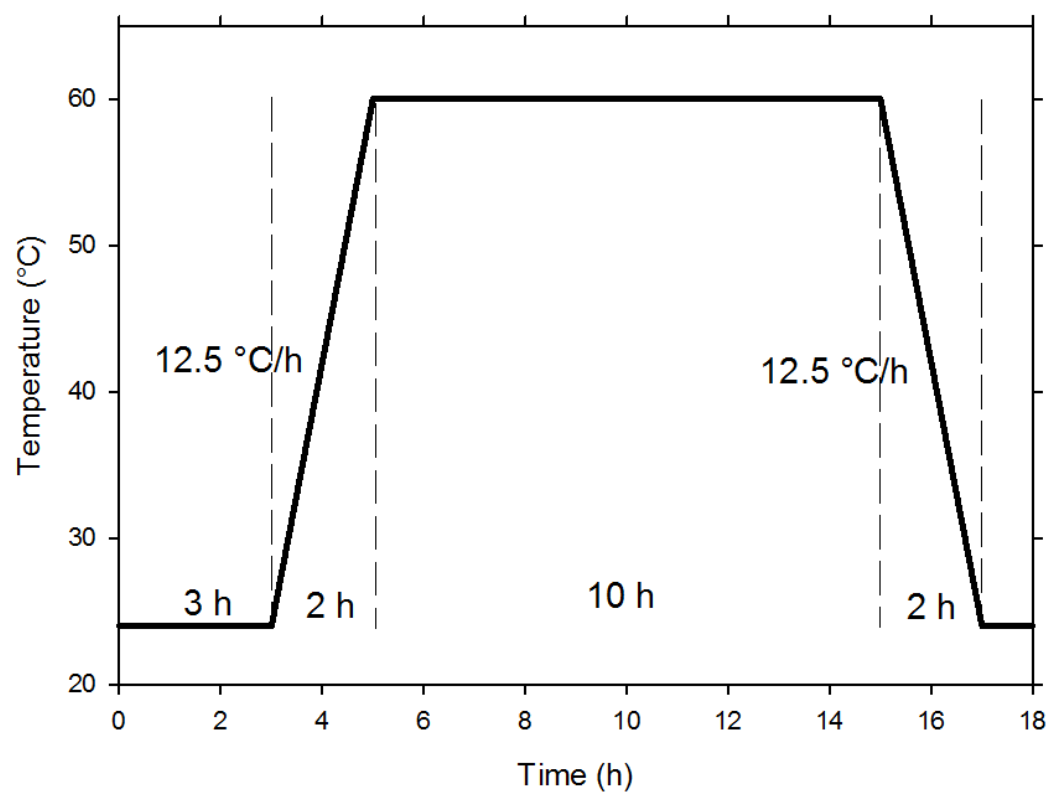

Figure 5. Steam curing schedule. 
After the curing process, the specimens were cut into seven pieces, each one corresponding to the region where the thermocouples were placed, with the aim of measuring the moisture content by gravimetric measurements and the degree of hydration by loss on ignition.

\subsubsection{NMR/MRI measurements during steam curing}

Type C specimens ( $\phi 40 \mathrm{~mm} \times 50 \mathrm{~mm}$ ) were cast with the same mortar in polystyrene insulated glass containers (Figure 6a). These specimens were subjected to the same steam curing as specimens Type B, and were removed from the environmental chamber every $2 \mathrm{~h}$ during 15 min for the NMR measurements. During testing, they were just covered with a thick cloth to reduce the heat loss (Figure 6b). The temperature at the sample holder was maintained at $35^{\circ} \mathrm{C}$. The CPMG [29] and the Single Point Imaging (SPI) techniques [30] were used in an Oxford Instruments Maran DRX HF 12/50 spectrometer. The CPMG technique allowed determination of the NMR signal amplitude and the transverse relaxation time $\mathrm{T}_{2}$, associated with the evaporable water and the pore size, respectively [31]. The SPI technique provided the water content distribution and the $\mathrm{T}_{2}{ }^{*}$ relaxation time by undertaking $\mathrm{T}_{2}{ }^{*}$ mapping [32] with 10 encoding times. This bulk and spatially resolved information was required to compare with the results obtained from the numerical simulation.

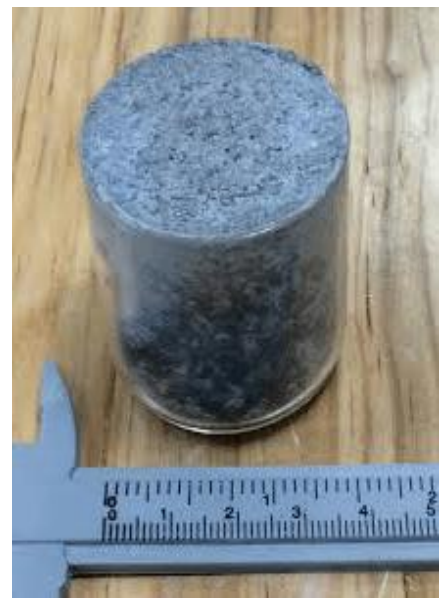

a)

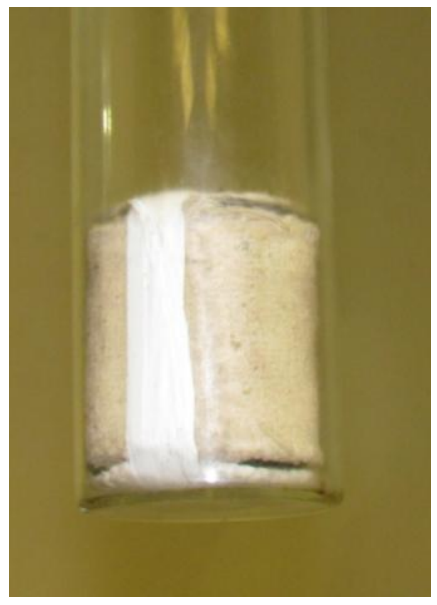

b)

Figure 6. a) Type $\mathrm{C}$ mortar specimens for nondestructive NMR/MRI measurements. b) Type $\mathrm{C}$ mortar specimens covered with a cloth in the sample holder.

\section{Mathematical Modeling approach}

\subsection{Geometries}

Three different geometries used in the experiments were modeled in COMSOL Multiphysics® version 4.4, in a 2-D axisymmetric geometry with the domains framed by cylindrical coordinates. The geometries represent the semi-adiabatic experiments with Type A specimens, the steam curing experiments with Type B specimens, and the NMR/MRI water profile measurements with Type C specimens. The dimensions of the geometries are given in millimeters.

Figure 7 a represents the geometry of the semi-adiabatic calorimetry experiment that consists of four subdomains, which represent the material $i$ : 1a) the cylinder of mortar; 2a) the container; 3a) the insulation wall, and 4a) the air between the top surface of the mortar and the container lid. Figure $7 b$ represents the geometry used in the steam curing experiment that is composed of three subdomains: 1b) the mortar cylinder, 2b) the PVC container, and 3b) polystyrene insulation. Figure 7c represents the geometry of the MRI specimens that consists of two subdomains: 1c) the mortar cylinder and 2c) the glass container. 


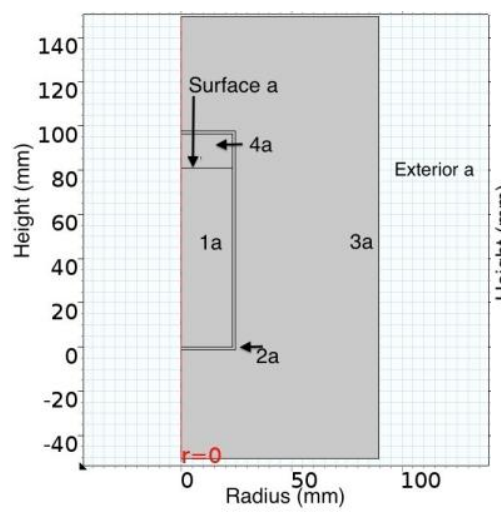

a)

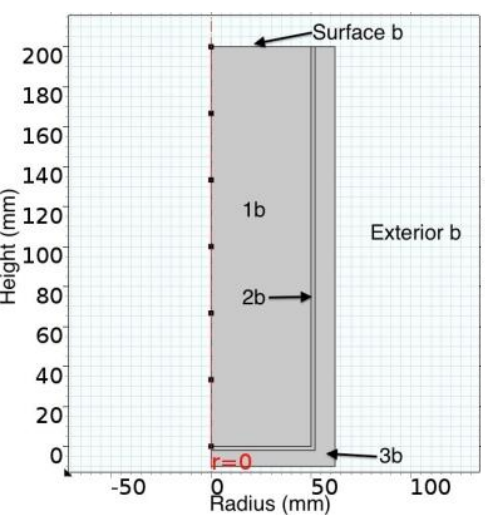

b)

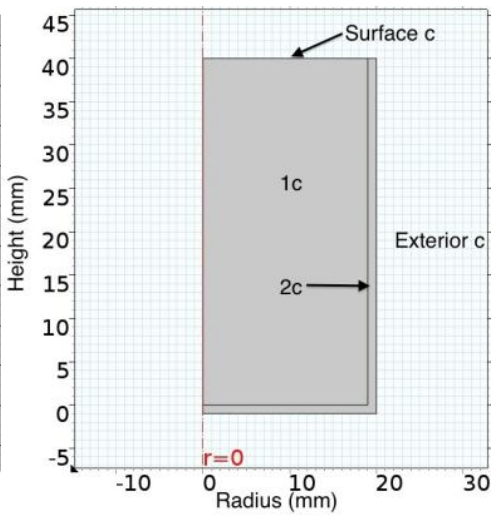

c )

Figure 7. 2D Axisymmetric geometries for a) the semi-adiabatic calorimetry experiment, b) steam curing experiment, and c) NMR/MRI experiments. The dimensions along the axes are in $\mathrm{mm}$.

\subsection{Hydration of cement in the form of the maturity equation coupled with equivalent age} In order to describe the cement hydration in mortar taking into account the changes in temperature, the equivalent time and the maturity equations were implemented in COMSOL Multiphysics ${ }^{\circledR}$ in the form of ordinary differential equations (ODE). The hydration reactions occur within the domain of the mortar in all geometries (subdomain 1). The maturity equation (Equation 4) was solved with respect to $t_{e}$ and shows a coupling between the equivalent time and the degree of hydration. The equivalent age (Equation 5) was implemented in COMSOL in the form of an ODE.

\subsection{Energy conservation}

The total energy conservation equation was used for all subdomains and geometries in the model. This allowed obtaining the total heat generated by the chemical reactions and the loss of heat to the container and subsequently to the thermal insulation wall. Equation 6 represents the balance of heat in the subdomain.

$$
{ }_{i} C_{p i} \frac{\partial T}{\partial t}=\nabla \cdot\left(k_{i} \nabla T\right)+Q_{i}
$$

where $i$ is the type of material, $k$ is the thermal conductivity of the material $i, C_{p}$ is its specific heat and $\rho$ is its density (Table 4 and Table 5).

The heat of hydration $Q$ is obtained from Equation (7) and is equal to zero for all subdomains that do not represent the mortar (subdomain $\neq 1$ ). The heat generation rate by the exothermic reactions in the subdomain 1 (Figure 7) is described as a derivative function of the degree of hydration with respect to time multiplied by the final heat of hydration, which was obtained by isothermal calorimetry measurements (Eq. 5).

$$
Q=\frac{d H}{d t}=\exp \frac{E}{R} \frac{1}{T_{r}} \frac{1}{T} \div \frac{H_{u} u}{t_{e}} \frac{t_{e}}{\div} \div \exp \frac{-}{t_{e}} \div
$$

where $H$ is the total enthalpy of hydration. The heat generation is obtained in joules per unit volume $\left(\mathrm{m}^{3}\right)$ of mortar.

The cumulative heat release was obtained by multiplying the degree of hydration by the final heat of hydration. The value of $H_{u}$ (Table 1), obtained by the sum of the heat generation of each phase, was used in the model in order to compute the final heat of hydration. The heat generation source was also considered in the energy conservation Equation (6), with the source term being expressed in units of $\mathrm{W} / \mathrm{m}^{3}$. 
Table 5. Properties of materials $i$ used in the experiments (from manufacturers)

\begin{tabular}{ccccc}
\hline Material & $\begin{array}{c}\text { Subdomain } \\
\text { number }\end{array}$ & $\begin{array}{c}\text { Density } \\
\left(\mathrm{kg} / \mathrm{m}^{3}\right)\end{array}$ & $\begin{array}{c}\text { Heat capacity } \\
{[\mathrm{J} /(\mathrm{kg} \cdot \mathrm{K})]}\end{array}$ & $\begin{array}{c}\text { Thermal } \\
\text { conductivity } \\
{[\mathrm{W} /(\mathrm{m} \cdot \mathrm{K})]}\end{array}$ \\
\hline LPDE container & $2 \mathrm{a}$ & 920 & 1400 & 0.36 \\
Micro-silica insulation & $3 \mathrm{a}$ & 230 & 800 & 0.037 \\
Polyvinyl chloride & $2 \mathrm{~b}$ & 1390 & 900 & 0.17 \\
Polystyrene & $3 \mathrm{~b}$ & 50 & 130 & 0.04 \\
Glass & $2 \mathrm{c}$ & 2203 & 703 & 1.38 \\
\hline
\end{tabular}

\subsection{Moisture conservation}

The moisture conservation balance (Equation 8) was applied to the subdomain 1 of mortar in all of the different geometries. This balance includes the transport of vapor $(h)$ and liquid water, which is the moisture content in the specimen. The physically bound water was not considered.

$$
{ }_{s} \frac{w}{t}=\frac{-}{x}{ }_{s} D_{l} \frac{w}{x}+{ }_{s} D_{v} \frac{h}{x}+S
$$

where $\rho_{s}$ is the density of the solid, $w$ is the moisture content ( $\mathrm{kg}$ of water $/ \mathrm{kg}$ of dry solid), $h$ is the relative humidity, and $S$ is the sink of water due to hydration reactions. The diffusion coefficients of liquid water $D_{l}$ (Equation 9) and water vapor $\rho_{s} D_{v}$ (Equation 10) were taken from [33], previously determined by Krus [34], with values for $a=0.0155 \mathrm{~g} /(\mathrm{m} \cdot \mathrm{d}), b=0.0055$, and $c=144$, as determined for the mortars in the current study:

$$
\begin{gathered}
{ }_{s} D_{v}=a \\
D_{l}=b \exp (c w)
\end{gathered}
$$

This coefficient depends on the moisture content. Therefore, it has a relationship with the degree of hydration in the sink term (Equation 8). Another term obtained from the calculated degree of hydration is the evaporable water sink $S$, which is the water consumed by the hydration reactions. $S$ will be considered in the equation of total moisture conservation (Equation 11).

$$
S={ }_{s} M_{f}^{c e m} w_{n} \frac{d}{d t}
$$

where $\rho_{\mathrm{s}}$ is the solid density and $w_{n}$ is the non-evaporable water necessary for hydration, obtained as the sum of the water necessary for the hydration of each phase in Table 1, and $M^{\text {cem }}{ }_{f}$ is the mass fraction of cement. The sink of water in the material is computed in units of $\mathrm{kg} /\left(\mathrm{m}^{2} \cdot \mathrm{s}\right)$.

\subsection{Boundary and initial conditions}

One of the assumptions of the model is that there exists a perfect contact between the materials. Therefore, in the heat conservation equation, the applied interior boundary condition in all geometries is a continuous boundary between air-mortar, mortar-container, and container-insulation (Equation 12).

$$
\overrightarrow{\mathbf{n}} \cdot\left[(k \nabla T)_{\Omega 1}-(k \nabla T)_{\Omega 2}\right]=0
$$

The mass conservation equation is applied to the domain of mortar, which has one boundary in contact with the surrounding environment. Therefore, the boundary conditions in this domain are zero flux conditions, except for the open surface (Table 6). The exterior boundaries in geometries b and $\mathrm{c}$ have a boundary condition as described by the Equation 13 .

$$
-\overrightarrow{\mathbf{n}} \cdot\left[\rho_{s} D_{l}(h) \frac{\partial w}{\partial x}+\rho_{s} D_{v}(h) \frac{\partial h}{\partial x}\right]=0
$$


Table 6. Boundary conditions

\begin{tabular}{|l|c|c|c|}
\hline Boundaries & Geometry a & Geometry b & Geometry c \\
\hline \multicolumn{2}{|c|}{ Heat Conservation Equation } \\
\hline $\begin{array}{l}\text { Surface } \\
\text { open) }\end{array}$ & $-\overrightarrow{\mathbf{n}} \cdot\left[(k \nabla T)_{\Omega 1}-(k \nabla T)_{\Omega 2}\right]=0_{(14)}$ & $-\overrightarrow{\mathbf{n}} \cdot(-k \nabla T)=h_{c}\left(T_{\text {ext }}-T\right)+\lambda_{\text {vap }} h_{m}\left(P_{\text {Vext }}-P_{V}\right)_{(15)}$ \\
\hline Exterior & \multicolumn{2}{|c|}{$-\overrightarrow{\mathbf{n}} \cdot(-k \nabla T)=h_{c}\left(T_{\text {ext }}-T\right)_{(16)}$} \\
\hline \multicolumn{4}{|c|}{$\begin{array}{c}\text { Mass conservation Equation } \\
\text { (open) }\end{array}$} \\
\hline
\end{tabular}

At the open surface of Type B and C specimens, a convective boundary condition was applied as expressed by Equation 15, where $h_{c}$ is the convective heat transfer coefficient, $\lambda_{\text {vap }}$ is the heat of vaporization, $h_{m}$ is the mass transfer coefficient at the surface, $P_{\text {vext }}$ is the vapor pressure in the surroundings [33], and $P_{v}$ is the vapor pressure inside the material. For type A specimens, $h_{c}$ takes a value of $15 \mathrm{~W} /\left(\mathrm{m}^{2} \cdot \mathrm{K}\right)[11]$ for an enclosed environment. In the case of steam curing conditions (Type B and C specimens), $h_{c}$ was calculated as $35.15 \mathrm{~W} /\left(\mathrm{m}^{2} \cdot \mathrm{K}\right)$ using a trial and error method (inverse method), adjusting the profiles of experimental temperature to match the simulated ones, until reaching the lowest mean quadratic error.

For comparison, Smilauer and Krejci [11] propose a value of $31 \mathrm{~W} /\left(\mathrm{m}^{2} \cdot \mathrm{K}\right)$ for a concrete surface surrounded by water. Under steam curing condition, the $h_{c}$ value increases as the temperature and the relative humidity inside the chamber increase. In the curing chamber there is not forced convection, but only natural convection. In order to compute the heat transfer coefficient, both the Grashof and Prandtl numbers are used, whose product gives the Raleigh number. The Raleigh number takes into account the buoyancy effect. The heat transfer coefficient has been computed by considering the experimental conditions in the chamber, obtaining an average value of $35 \mathrm{~W} /\left(\mathrm{m}^{2}\right.$ $\cdot \mathrm{K})$.

The boundary condition (equation 17) for the mass conservation equation considers a convective mass transfer coefficient of $6 \times 10^{-3} \mathrm{~g} /\left(\mathrm{m}^{2} \cdot \mathrm{h} \cdot \mathrm{Pa}\right)$. This value was calculated using a trial and error method by comparing the average experimental kinetics with the simulated ones, until reaching the lowest mean quadratic error. Villmman et al [33] proposed a value of $h_{m}=5 \times 10^{-3} \mathrm{~g} / \mathrm{m}^{2} \cdot \mathrm{h} \cdot \mathrm{Pa}$ for mortar with $w / c=0.40$ exposed to $23{ }^{\circ} \mathrm{C}$ and $35 \%$ relative humidity. The initial conditions were a moisture content of $0.0885 \mathrm{~kg}$ water $/ \mathrm{kg}$ dry solid and a temperature of $23^{\circ} \mathrm{C}$ for the semi-adiabatic experiments, and $24^{\circ} \mathrm{C}$ for the steam curing conditions (Figure 5).

\subsection{Numerical Solution.}

A coupled model is employed for the simulation. Figure 8 shows the components of the computational model and the couplings. The couplings between the energy conservation equations and mass conservation equations are ensured by the boundary conditions. The equivalent time is an input for the maturity equation, which computes the degree of hydration. The degree of hydration is linked to the mass conservation equation by the sink term (S), which indicates the loss of moisture due to chemical reaction. The degree of hydration is also connected to the energy conservation equation by the source term $(\mathrm{Q})$, which takes into account the exothermic nature of the reaction. The constitutive equations are shown in Figure 8. 


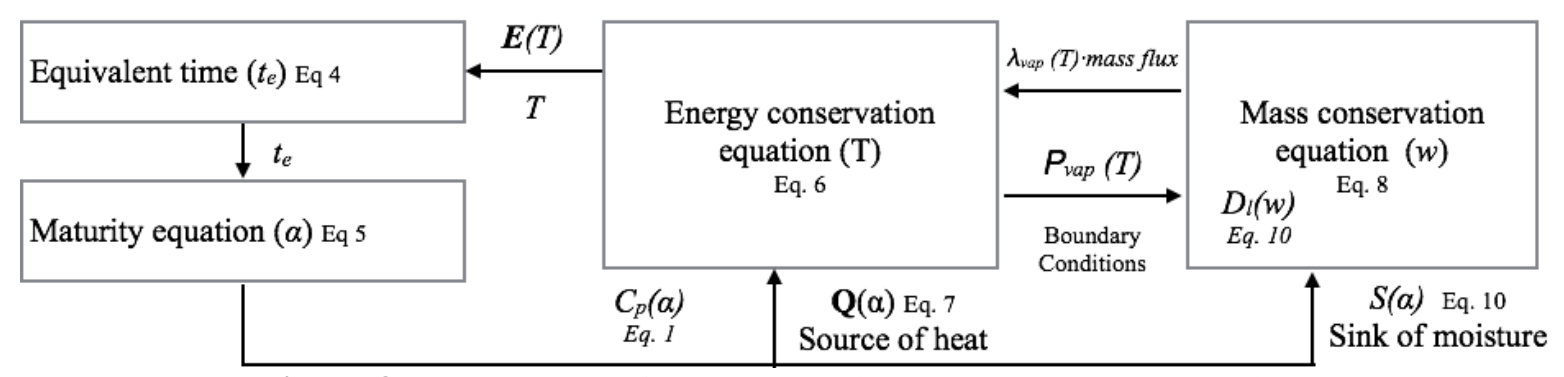

Figure 8. Components of the computational model and the couplings

Using a relative tolerance of 0.01 , and a time step of $6 \mathrm{~min}$, the set of equations was solved. The triangular elements solved and the degrees of freedom in each geometry were as follows: Geometry a Elements $=1913$ DOFs $=10016$, Geometry b Elements=1720 DOFs $=19569$, and Geometry c Elements $=551$ DOFs $=8686$.

\section{Results and discussion}

\subsection{Semi-adiabatic experiment simulation}

Figure 9 shows the comparison of temperature evolution between that measured for the Type A cylinders in the semi-adiabatic calorimetry experiments (dotted line) and the result of the simulation using the presented model (solid line). A good agreement is observed between the experimental and the simulated data. The temperature first increases due to the heat generated by cement hydration. The temperature distribution is homogeneous due to the low thermal conductivity of the microsilica insulation and to the mortar's thermal conductivity that is dominated by the silica sand that represents $64 \%$ by mass of the specimen. The simulated maximum temperature of $34.7{ }^{\circ} \mathrm{C}$ in this specimen was reached at $9.5 \mathrm{~h}$ (Figure $9 \mathrm{~b}$ ).

The temperature evolution shows the heating and cooling phases. Residuals were obtained from the difference between the simulated and experimental data, obtaining a maximum difference of $2.5^{\circ} \mathrm{C}$, in the heating phase. The difference was positive throughout the hydration process, which means an over-prediction of temperature by the model. The residuals dropped below $1{ }^{\circ} \mathrm{C}$ in the cooling phase. It needs to be taken into account that there is a continuous boundary condition (Equation 14) on the surface of the specimen and that there is air trapped between the lid and mortar; therefore the model does not consider water evaporation (and its accompanying evaporative cooling) and this may contribute to the temperature over-predictions. In support of this, liquid water has been sometimes observed at the top surface of similar semi-adiabatic calorimetry specimens when they were removed from their surrounding insulation after $3 \mathrm{~d}$. In the semi-adiabatic calorimetry test, the value assigned to the thermal conductivity of the insulation was critical in obtaining reasonable agreement between the experiments and the simulation. The employed value from Table 5 was obtained from direct measurement on the in service material using the TPS method and was significantly higher than the value of about $0.02 \mathrm{~W} /(\mathrm{m} \cdot \mathrm{K})$ supplied by the manufacturer for new material. 


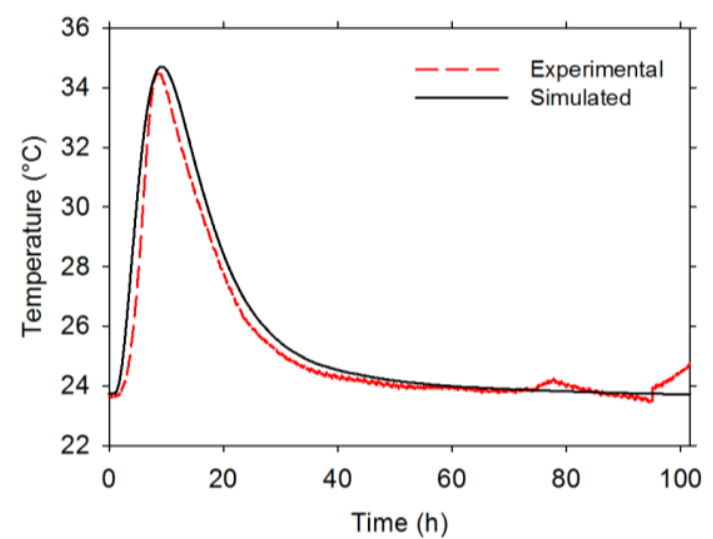

a)

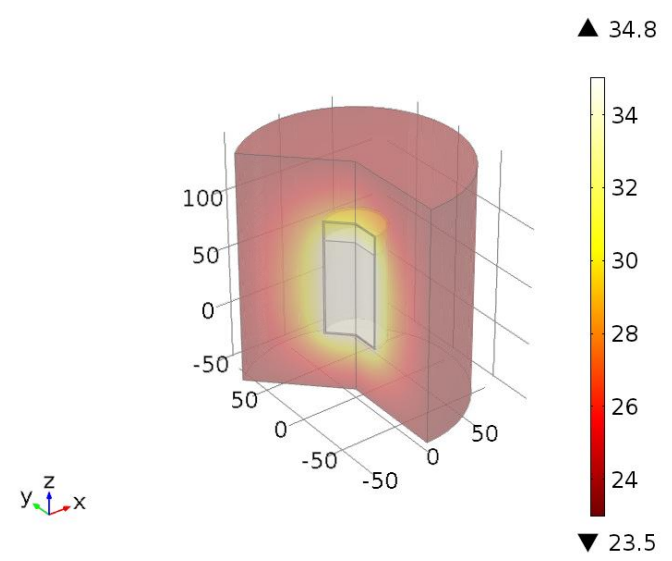

b)

Figure 9. a) Experimental and simulated temperature evolution in specimens Type A during the semi-adiabatic calorimetry test, and b). Temperature distribution in the simulated semi adiabatic calorimetry experiments at $9.5 \mathrm{~h}$.

\subsection{Steam curing experiment simulation}

\subsubsection{Type B specimens}

Figure 10 shows the experimental and modeled temperature distribution in the Type B specimen, using the maturity equation. The actual steam curing cycle used in the simulation differs from the target cycle shown in Figure 5, especially in the period of constant temperature, and in the cooling phase. At the beginning, the temperature increases at the surface of the specimen, where hydration reactions are accelerated by contact with the water vapor. The heat slowly flows into the cylinder because of the relatively low thermal conductivity of the hydrating mortar. At $6 \mathrm{~h}$, all the thermocouples show the same temperature of $58^{\circ} \mathrm{C}$, and from this time the internal temperature exceeds the surface temperature due to the hydration reactions and to the thermal insulation around the specimen. Then, the heat is transferred more rapidly because of the increased thermal conductivity and the decrease of heat capacity as hydration proceeds [23]. The residuals show a maximum over-prediction of $5{ }^{\circ} \mathrm{C}$ in the heating phase in the evolution of temperature of the thermocouples located in the insulated side (thermocouples 5 and 7). The residuals decreased to $3{ }^{\circ} \mathrm{C}$ during the period of constant temperature, until $15 \mathrm{~h}$.

The temperature of the Type B specimen shows an increase in the insulated side during the first hours of hydration due to the exothermic nature of the hydration reactions. Conversely, in the Type $\mathrm{C}$ specimen, there is no insulation barrier and the specimen is very small so that the temperature is nearly uniform at $12 \mathrm{~h}$.

The main parameters affecting the temperature distribution during curing are the heat generation by the chemical reactions, the thermal conductivity of the insulation, and the thermal conductivity and heat capacity of the mortar. The convective heat transfer coefficient and surface evaporation, both external factors, have little influence due to the occurrence of only natural convection and the maintenance of a high relative humidity in the curing chamber.

Figure 11 shows the experimental and simulated final moisture distribution at $18 \mathrm{~h}$. To match the experimental and simulated moisture content, it was necessary to calculate by inverse analysis the mass transfer coefficient $h_{m}$ at the surface (Equation 17), in order to get a sense of the amount of water lost at the surface. This coefficient was considered constant throughout the curing process (See section 3.5) and it is on the order of those obtained by Villmann et al [33] in their study. However, the water lost at the surface also depends on the vapor pressure and on the relative humidity and temperature of the curing chamber (Equation 17). Comparing the simulated and experimental final moisture content profiles, the maximum deviation of the residuals was $0.02 \mathrm{~kg}$ 
water/kg dry solid, which occurred at the insulated boundary. Moreover, due to the saturation conditions of the chamber, the amount of water evaporating at the surface is less than $1 \%$ of the total mass of the cylinder; then, the most important sink of moisture (free water) is due to the chemical reactions (cement hydration).

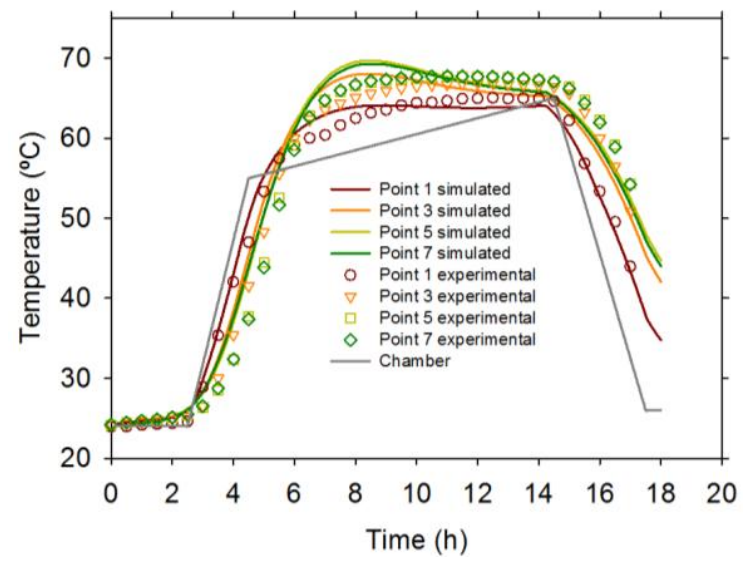

a)

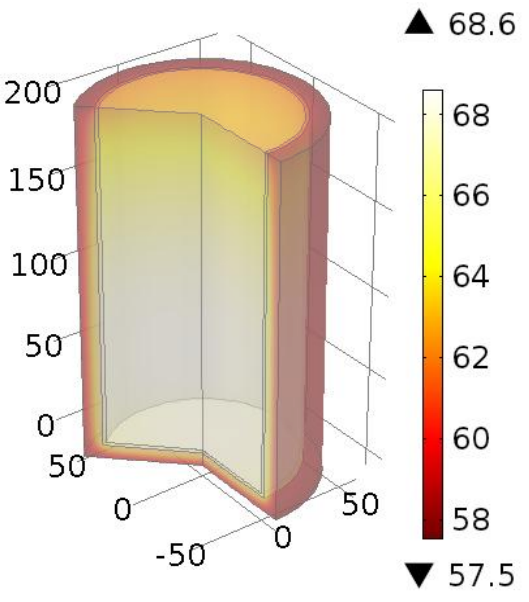

b)

Figure 10. a) Comparison of simulated and experimental temperature evolution during steam curing (Type B specimen), b) Temperature distribution $\left({ }^{\circ} \mathrm{C}\right)$ in the simulated vapor curing experiments at $7 \mathrm{~h}$.

Comparison of simulated and experimental final degree of hydration is also shown in Figure 11. A maximum residual of -0.05 was obtained, indicating that the simulations underestimate the degree of hydration. This is because the parameters for the maturity equation were obtained under isothermal and sealed conditions (section 2.2.1.3) and steam curing was performed under nonisothermal conditions with a source of additional water. It is observed that the degree of hydration is more or less homogeneous at the end of steam curing process. An experimental average value of 0.52 was obtained, while the simulated value was 0.5 .

\subsubsection{Type $\mathrm{C}$ specimens}

Figure 12 shows the simulated and measured MRI average moisture content during steam curing. The mass transfer coefficient calculated for the Type B specimen was used for the simulations of the type $\mathrm{C}$ specimen under the same steam curing conditions. A similar trend in the evolution of moisture content is observed. A maximum over-prediction of about $0.0055 \mathrm{~kg}$ water $/ \mathrm{kg}$ dry solid was found in the first $5 \mathrm{~h}$ that is consistent with the over-predictions in temperature evolution in the type B specimen. However, the shape of the moisture loss distribution during steam curing depends not only on the diffusion coefficient of liquid water and the vapor diffusion coefficient, but also on the hydration reactions. The diffusion coefficients were obtained by comparing and fitting the kinetics while adjusting the values of the parameters, especially the diffusion coefficient of liquid water (via the values of $b$ and $c$ in equation 10). In order to capture the physics of our experiments, a mass transfer coefficient $h_{m}$ was considered. The simulated final moisture content for the Type B and $\mathrm{C}$ specimens was $0.062 \mathrm{~kg}$ water $/ \mathrm{kg}$ dry solid.

The shape of the moisture content distribution in Figure 12 depends mainly on the mass transfer coefficient and surface diffusion coefficient of liquid water. During hydration, the porosity and the pore size decrease, while the tortuosity increases with increasing degree of hydration, because the volume of hydration products is larger than the volume of solid (powder) reactants. This phenomenon influences the diffusion coefficient of the liquid $D_{l}$, which has a variation from about 
$10^{-8}$ to $10^{-10} \mathrm{~m}^{2} / \mathrm{s}$ for cement pastes (Figure 13 ). On the other hand, the NMR $T_{2}$ relaxation times are indicative of the porosity refinement caused by cement hydration, as it is related to the

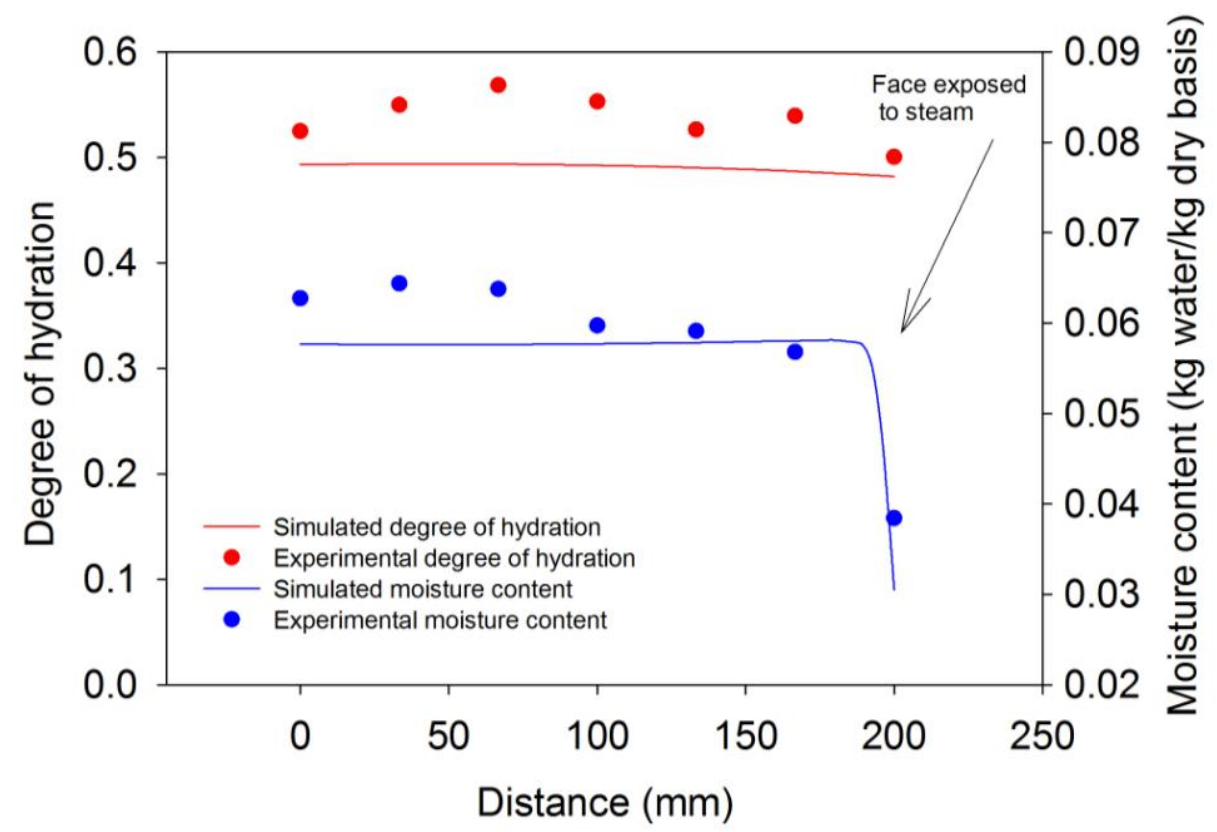

Figure 11. Comparison of final moisture content (right axis) and the final degree of hydration by LOI (left axis). Both parameters were obtained in the $\mathrm{z}$ direction of Type B specimens. Symbols indicate the measured values and the solid line is the simulated values.

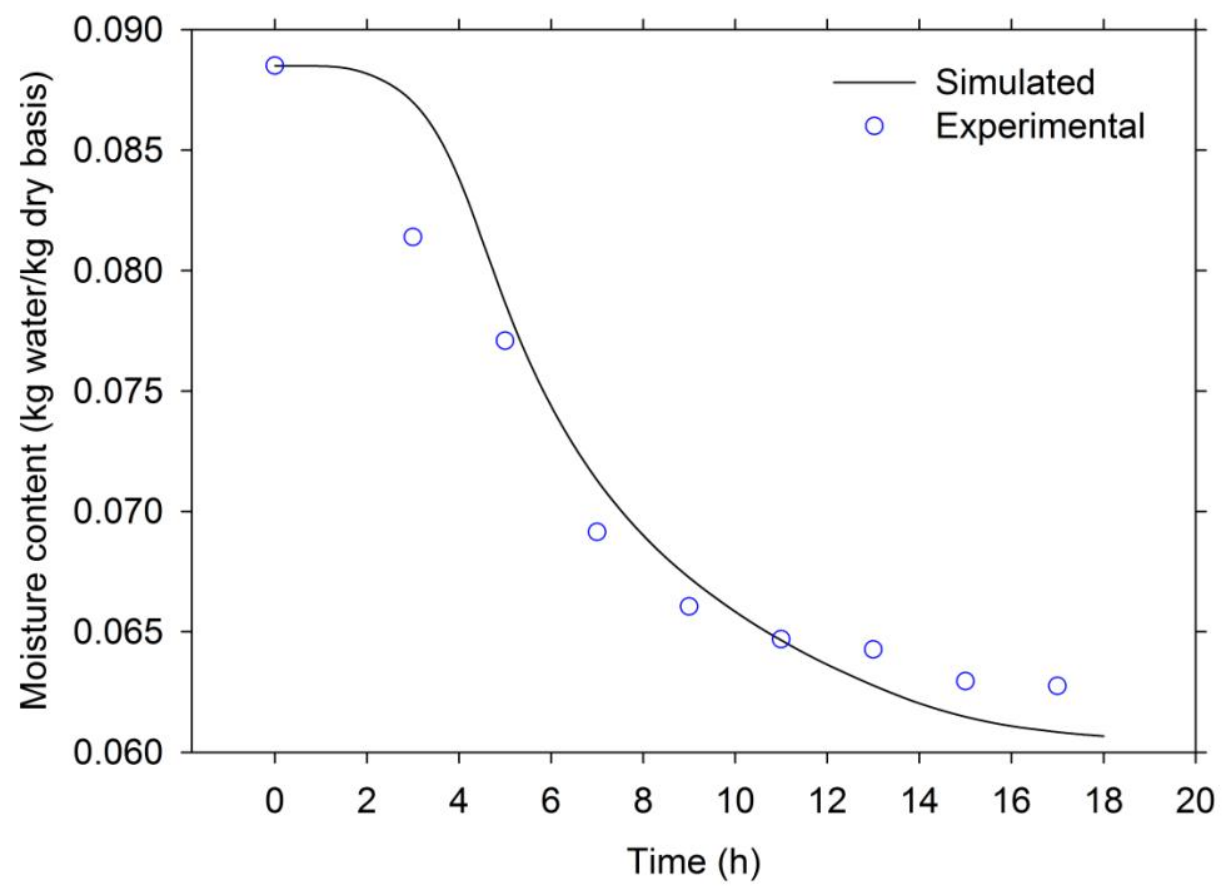

Figure 12. Comparison between time-dependent moisture content simulated and experimentally obtained from MRI moisture content profiles in Type C specimens. Root-mean-square-error (RMSE) was 0.0027. 
surface to volume ratio of the pore system [31], as indicated by Equation 18. It states that as the pores get smaller, the surface to volume ratio increases. Plotting the diffusivity function (Equation 10) and the $T_{2}$ relaxation time versus hydration time, it is observed that the $T_{2}$ variations follow a similar behavior as the diffusivity function.

$$
\frac{1}{T_{2}}=2 \frac{S_{p}}{V_{p}}
$$

where $\rho 2$ is the $T_{2}$ surface relaxivity and $S_{p} / V_{p}$ is the surface to volume ratio of the pore system. The diffusion coefficient was computed by fitting equation 10 to the experimental data of moisture content (Figure 12). This coefficient is shown in figure 13.

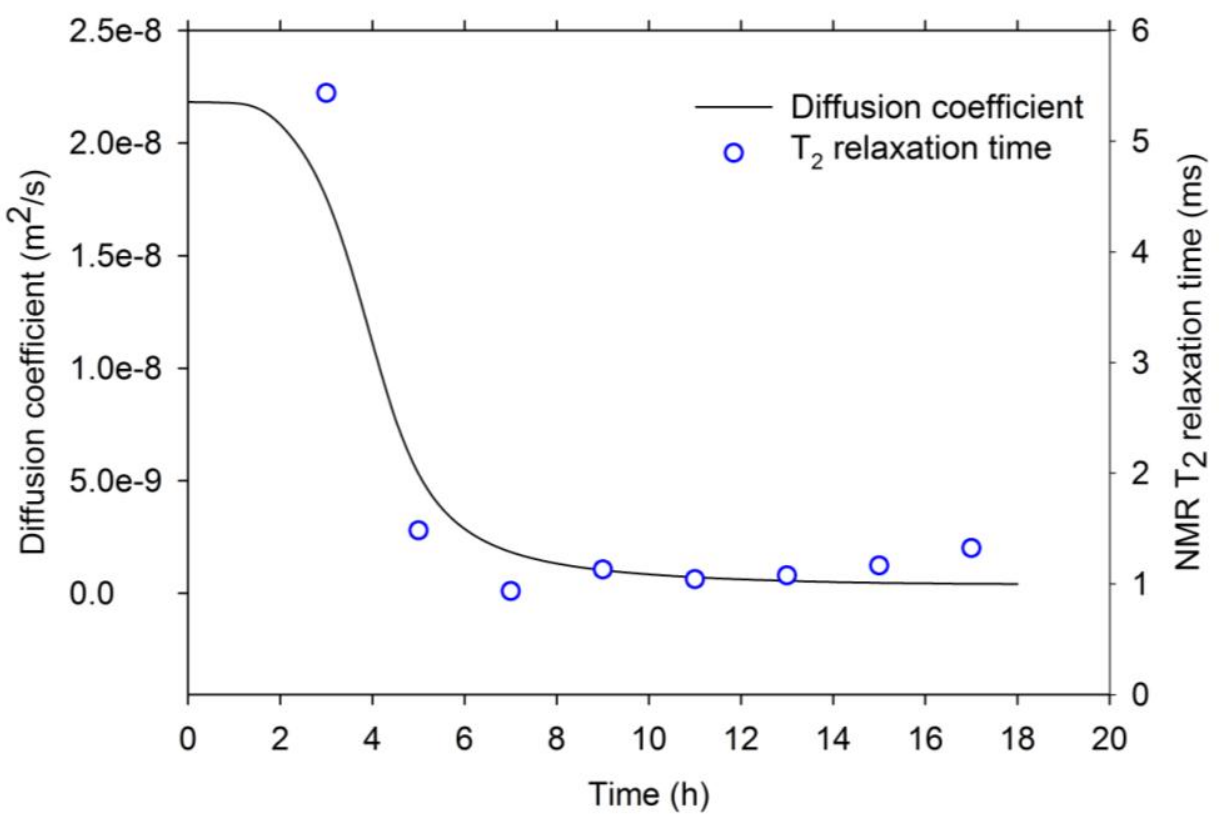

Figure 13. Average diffusion coefficient (simulated) and relaxation times in a hydrating mortar sample Type $\mathrm{C}$. The NMR $\mathrm{T}_{2}$ relaxation time plotted corresponds to the long component.

Figure 14 shows the comparison between the simulated and experimental profiles. The experimental data obtained by MRI show the pattern of evaporable water consumption by the chemical reaction between cement and water. The major consumption of evaporable water due to hydration reactions occurs from $3 \mathrm{~h}$ to $7 \mathrm{~h}$ during the steam curing process. The higher reduction in moisture content at the region close to the face in contact with the steam could be caused by both drying and cement hydration. The moisture loss due to drying was measured to be less than $1 \%$ of the mass of the specimen. The simulated profiles indicate that the model correctly describes the pattern of evaporable moisture decrease, including the moisture gradient produced at the face exposed to the steam at the ages of $11 \mathrm{~h}$ and $17 \mathrm{~h}$. 


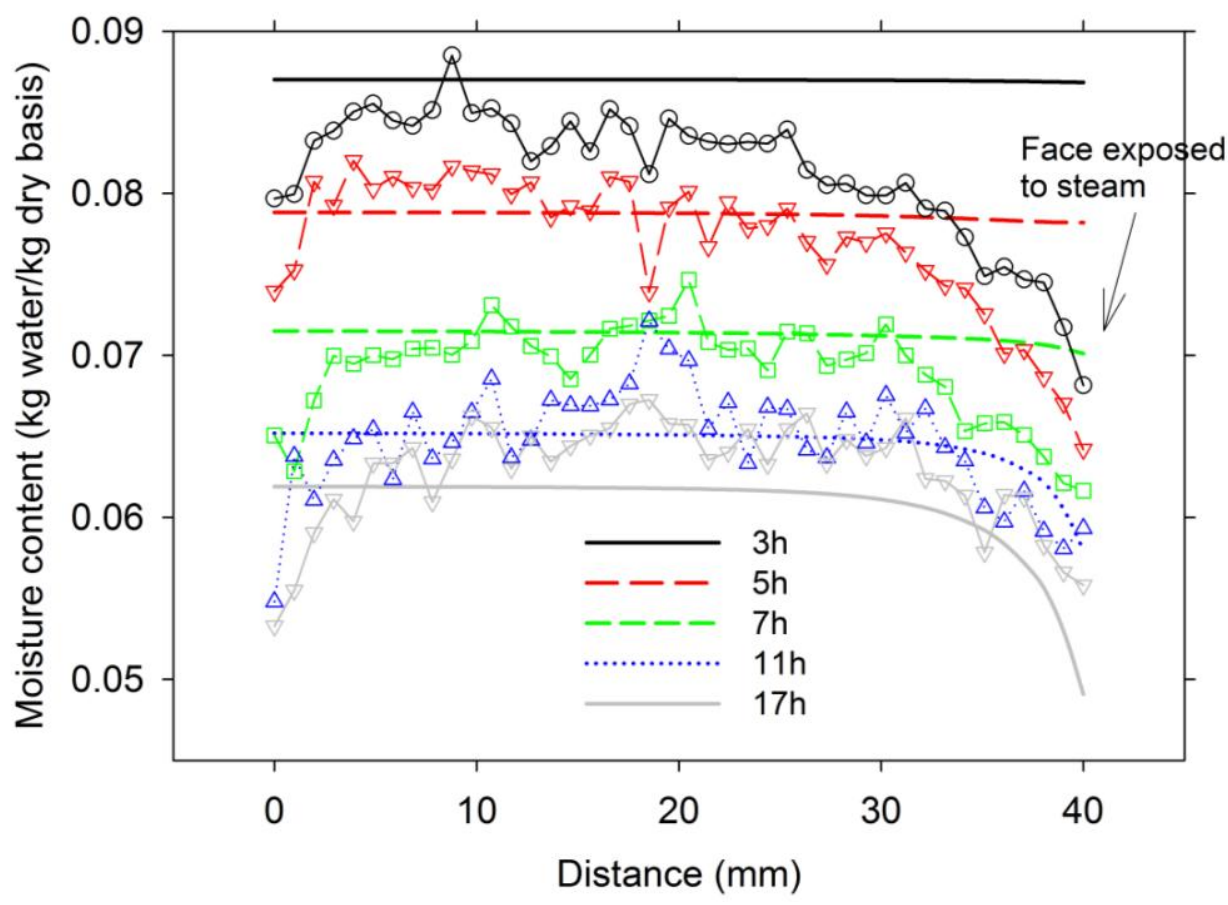

Figure 14. Simulated (solid lines) and experimental (dotted lines) spatial distribution of moisture content in $\mathrm{z}$ direction for the Type $\mathrm{C}$ specimen.

\section{Conclusions}

A Multiphysics model that describes heat conduction, degree of hydration and moisture content in Portland cement mortar specimens was developed. It describes hydration with variation of temperature by using the equivalent-age maturity method. The variation of temperature and moisture content are described using total conservation equations for heat and moisture, and the results are compared with experimental data. The model was solved in order to simulate two conditions: semi-adiabatic and steam curing conditions.

The experimental thermal conductivity of mortar obtained by the transient plane source technique shows minimal changes during hydration, having a maximum change of $0.4 \mathrm{~W} /\left(\mathrm{m}^{\circ} \mathrm{K}\right)$.

The nuclear magnetic resonance measurements show a $T_{2}$ relaxation time step decrease similar to the decrease of the diffusion coefficient. It can be explained taking into account that the decrease in $T_{2}$ is related to the capillary porosity refinement and the diffusion coefficient is also affected by the decrease in the pore size.

The maturity model correctly describes the evolution of heat and the degree of hydration. The experimental temperature and the simulated results had a maximum residual value of $2.5^{\circ} \mathrm{C}$ and $5^{\circ} \mathrm{C}$ for semi-adiabatic conditions and steam curing conditions, respectively. Evaporation losses in the specimens were less than $1 \%$ by mass, indicating that evaporable water loss during steam curing was mainly due to the hydration reactions.

The simulated degree of hydration under steam curing conditions was 0.50 , with a maximum residual of -0.05 , indicating that the simulations underestimate the actual degree of hydration. This is because the parameters for the maturity equation were obtained under isothermal conditions and the steam curing was performed under non-isothermal conditions with a source of additional water. It is observed that the degree of hydration is more or less homogeneous at the end of the steam curing process.

The experimental and simulated moisture content profiles indicate that the major consumption of evaporable water during steam curing is from $3 \mathrm{~h}$ to $7 \mathrm{~h}$. The model describes the pattern of 
evaporable water consumption by chemical reaction and evaporation at the surface of the specimen, compared with the experimental profiles.

\section{Acknowledgements}

E. Hernández-Bautista acknowledges NIST and the staff of their Materials and Structural Systems Division, Conacyt for the PhD scholarship and the Instituto Politécnico Nacional for the PIFI scholarship. P. Cano and S. Sandoval acknowledge SIP from IPN for funding the projects ID codes 20140613 and 20144660, respectively.

\section{References}

[1] Kosmatka SH, Kerkhoff B, and Panarese WC. Design and Control Design and Control of Concrete Mixtures, Fourteenth. Portland Cement Association 2003; p. 360.

[2] Xu Q, Ruiz J M, Hu J, Wang K., and Rasmussen RO. Modeling hydration properties and temperature developments of early-age concrete pavement using calorimetry tests. Thermochim. Acta 2011; 512(1-2): 76-85.

[3] Soroka I. and Bentur HJA. Short-term steam-curing and concrete later-age strength materiaux et constructions 1978;11(62): pp. 93-96.

[4] Chini AR Effect of elevated curing temperatures on the strength and durability of concrete Materials and Structures 2005; 38(281): 673-679.

[5] Won I, Na Y, Kim JT, and Kim S. Energy-efficient algorithms of the steam curing for the in situ production of precast concrete members. Energy Build 2013; 64: pp. 275-284.

[6] Ramezanianpour AA. Khazali MH and Vosoughi P. Effect of steam curing cycles on strength and durability of SCC: A case study in precast concrete. Construction and Building Materials 2013; 49: pp. 807-813.

[7] Kjellsen K. Heat curing and post-heat curing regimes of high- performance concrete: influence on microstructure and C-S-H composition. Cement and Concrete Research 1996; 26(2): pp. 295-307.

[8] Ba M, Qian C, Guo X, and Han X. Effects of steam curing on strength and porous structure of concrete with low water/binder ratio. Construction and Building Materials 2011; 25(1): pp. $123-128$.

[9] Zhi-min, HE, Guang-cheng L, and You-jun XIE. Influence of subsequent curing on water sorptivity and pore structure of steam-cured concrete. J. Cent. South Univ, 2012; 12(19): pp. $1155-1162$.

[10] Ozkul MH, Efficiency of accelerated curing in concrete. Cement and Concrete Research 2001;31: pp. 1351-1357. 
[11] Smilauer V and Krejci T. Multiscale model for temperature distribution in hydrating concrete International Journal for Multiscale Computational Engineering 2009; 7(2).

[12] Davie CT, Pearce CJ and Bićanić N. Coupled Heat and Moisture Transport in Concrete at Elevated Temperatures-Effects of Capillary Pressure and Adsorbed Water. Numerical Heat Transfer, Part A: Applications 2006; 49(8) : pp. 733-763.

[13] Jeong JH , Ligang W, and Zollinger DG. A temperature and moisture module for hydrating Portland cement concrete pavements. 7th International Conference on Concrete Pavements, 2001; pp. 9-13.

[14] Sciumè G and Schrefler BA. A multi-scale numerical model for concrete at early age. XVIII GIMC Conference. Siracusa 2010.

[15] Zhang B and Yu X. Multiphysics for Early Stage Cement Hydration: Theoretical Framework Advanced Materials Research 2011; 216: 4247-4250.

[16] Giovanni D, Luzio and Cusatis G. Hygro-Thermo-Chemical Modeling of High Performance Concrete I : Theory Introduction. Cement \& Concrete Composites 2009; 31(5): pp. 301-308.

[17] Lawrence AM, Tia M, and Bergin M. Considerations for Handling of Mass Concrete : Control of Internal Restraint. ACI Materials Journal 2014;111: pp. 3-11.

[18] ASTM. C188 Standard Test Method for Density of Hydraulic Cement ASTM International, 2009.

[19] ASTM. Standard Practice for Mechanical Mixing of Hydraulic Cement Pastes and Mortars of Plastic Consistency. ASTM International 2010: C305(06); pp. 6-8.

[20] Bentz DP Waller V and de Larrard F. Prediction of adiabatic temperature rise in conventional and high-performance concretes using a 3-D microstructural model. Cement and Concrete Research 1998; 28 (2): pp. 285-297.

[21] Hua C, Ehrlacher A, and Acker P. Analyses and model of the autogeous shrinkage of hardening cement paste II Modelling at scale of hydrating grains. Cement and Concrete Research 1997; 27(2): pp. 245-258.

[22] Gustavsson SE. Transient plane source technique for thermal conductivity and thermal diffusivity measurements of solid materials. Rev. Sci. Instrum 1991; 62: pp. 797-804.

[23] Bentz DP. Transient plane source measurements of the thermal properties of hydrating cement pastes. Materials and Structures 2007; 40: pp. 1073-1080.

[24] Thermometric AB. HandbookTAM Air Calorimeter. New Castle, 2011; p. 63.

[25] Schindler AK. Temperature Control During Construction to Improve the Long Term Performance of Portland Cement Concrete Pavements. Texas Department of Transportation, 2002. 
[26] Jonasson JE, Groth P. and Hedlund H. Modeling of temperature and moisture field in concrete to study early age movements as a basis for stress analysis. In Ruper springenschimid, editor. Proceedings of the International RILEM Symposium on Thermal Cracking in Concrete at Early Ages. London 1995: 45-52.

[27] RILEM. Adiabatic and semi-adiabatic calorimetry to determine the temperature increase in concrete due to hydration heat of the cement. Materials and Structures 1997:30(8), 451-464.

[28] American Concrete Institute. ACI 517-2R-80 Accelerated Curing of Concrete at Atmospheric Pressure. ACI Journal 1980; 77: pp. 429-448.

[29] Meiboom S and Gill D. Modified spin-echo method for measuring nuclear relaxation times Review of Scientific Instruments 1958; 29: pp. 688-691.

[30] Gravina S and. Cory DG. Sensitivity and resolution of constant-time imaging Journal of Magnetic Resonance 1994: Series B 1: pp. 53-61.

[31] Halperin WP. Microstructure Determination of Cement Pastes by NMR and Conventional Techniques advances in cement base materials 1993;1(2:) pp. 67-76

[32] Prado PJ, Balcom BJS Beya D, Armstrong RL, and Bremner TW. Concrete/mortar water phase transition studied by single-point MRI methods. Magn. Reson. Imaging1998:16(1): pp. 521523.

[33] Villmann B, Slowik V, Wittmann FH, Vontobel P, and Hovind J. Time-dependent Moisture Distribution in Drying Cement Mortars. Results of Neutron Radiography and Inverse Analysis of Drying Tests Determination of Moisture Transport Parameters and Moisture Profiles by Inverse Analysis. Restoration of Buildings and Monuments 2014; 20(1): pp. 49-62.

[34] Krus M. Feuchtetransport- und Speicherko effizienten poröser mineralischer Baustoffe. PhD thesis. Universität Stutt, 1995. 